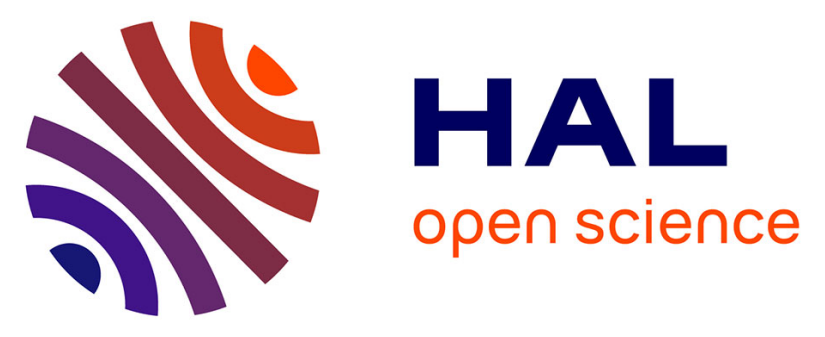

\title{
Fatigue behaviour of flax-basalt/epoxy hybrid composites in comparison with non-hybrid composites
}

\author{
Maria Carolina Seghini, Fabienne Touchard, Fabrizio Sarasini, Laurence \\ Chocinski-Arnault, M.R. Ricciardi, V. Antonucci, Jacopo Tirillo
}

\section{- To cite this version:}

Maria Carolina Seghini, Fabienne Touchard, Fabrizio Sarasini, Laurence Chocinski-Arnault, M.R. Ricciardi, et al.. Fatigue behaviour of flax-basalt/epoxy hybrid composites in comparison with non-hybrid composites. International Journal of Fatigue, 2020, 139, pp.105800. 10.1016/j.ijfatigue.2020.105800 . hal-03008663

\section{HAL Id: hal-03008663 https://hal.science/hal-03008663}

Submitted on 16 Nov 2020

HAL is a multi-disciplinary open access archive for the deposit and dissemination of scientific research documents, whether they are published or not. The documents may come from teaching and research institutions in France or abroad, or from public or private research centers.
L'archive ouverte pluridisciplinaire HAL, est destinée au dépôt et à la diffusion de documents scientifiques de niveau recherche, publiés ou non, émanant des établissements d'enseignement et de recherche français ou étrangers, des laboratoires publics ou privés. 


\title{
Fatigue behaviour of flax-basalt/epoxy hybrid composites in comparison with non-hybrid composites
}

Maria Carolina SEGHINI ${ }^{1,2}$, Fabienne TOUCHARD ${ }^{2 *}$, Fabrizio SARASINI ${ }^{1}$, Laurence

CHOCINSKI-ARNAULT ${ }^{2}$, Maria Rosaria RICCIARDI ${ }^{3}$, Vincenza ANTONUCCI ${ }^{3}$, Jacopo TIRILLÒ ${ }^{1}$

${ }^{1}$ Department of Chemical Engineering Materials Environment and UdR INSTM, Sapienza-Università di Roma, Via Eudossiana 18, 00184 Rome, Italy

${ }^{2}$ Institut PPRIME, CNRS-ENSMA-Université de Poitiers, Département Physique et Mécanique des Matériaux, ENSMA, 1, Av. Clément Ader, B.P. 40109, 86961 Futuroscope Cedex, France

${ }^{3}$ Institute for Polymer, Composites and Biomaterials, National Research Council, Piazzale Enrico Fermi, 1, 80055 Portici, Italy

*: corresponding author: fabienne.touchard@ensma.fr

\begin{abstract}
:
Investigation on the fatigue life of hybrid composites is critical to extend their structural applications. However, there is a lack of research on fatigue performance of hybrid composites. In this study, the fatigue life of a flax-basalt woven-ply hybrid composite is investigated and compared with the behaviour of $100 \%$ flax and $100 \%$ basalt composites. After the optimisation of the epoxy resin curing cycle, tension-tension fatigue tests were performed on samples with two orientations, $0^{\circ} / 90^{\circ}$ and $\pm 45^{\circ}$. S-N curves with absolute values and with normalised values are discussed. Results showed that the hybridisation was able to produce a positive effect on the fatigue resistance of basalt laminates: a better normalised fatigue resistance was obtained for the hybrid composite in comparison with the $100 \%$ basalt one in both orientations. A two-parameter fatigue life model was then applied and showed its ability to predict the fatigue behaviour of the hybrid composite for the two orientations. An analysis of damage mechanisms by means of infrared thermography and scanning electron microscopy allowed observing the different types of damage occurring during fatigue loading in hybrid composites.
\end{abstract}

Keywords: Polymer matrix composites; S-N curves; Fatigue modelling; Fractography; Damage 


\section{Introduction}

In the last two decades, the development of plant fibre reinforced polymer matrix composites has attracted great interest due to their properties and environmentally friendly character. In particular, lignocellulosic fibres such as flax, hemp, jute, sisal and abaca have been proposed as substitutes of traditional glass fibres [1]. These fibres offer several advantages over conventional synthetic ones, such as low density, low cost, good specific mechanical properties, wide availability and biodegradability [2]. However, despite their benefits, the natural fibres have also some drawbacks. Indeed, they show high moisture sensitivity, low thermal stability, low microbial resistance and poor compatibility with polymeric matrices, which makes their use inconvenient in semi- or structural applications [3]. Therefore, the development of hybrid composite materials, by introducing different types of fibres aiming at overcoming the drawbacks of composites reinforced with only one type of fibres, can represent a very attractive way of solving this problem. In this regard, hybridisation of plies of plant and synthetic fibres represents a significant strategy to reduce weight and carbon footprint of traditional composite materials, while retaining a sufficient mechanical performance to permit structural applications. In particular, it has been shown that hybrid composite materials can improve impact and bending resistance in comparison with non-hybrid ones [4-7]. According to Dong [8], hybrid composites including plant fibres were fabricated most frequently with glass fibres. Several works have given an overview on the different properties of glass-plant hybrid composites [9-11]. In recent years, there has been substantial interest in the application of basalt fibres as reinforcement of polymer matrices mainly as replacement for glass fibres in view of their advantages in terms of environmental cost relative to their chemical and mechanical properties [12-14]. This has triggered the development of hybrids including plant fibre and basalt fibre laminates [15-20].

It is known that fatigue loadings are responsible for many, if not most, failures in engineering structures [21]. Indeed, dynamic repetitive loadings (vibration, rotation, wind and wave action, turbulence, pressurisation, etc.) at levels much lower than ultimate strengths can result in sudden and catastrophic failure due to internal damage accumulation over a period of time. Hence, the fatigue behaviour of the material is vital in almost all engineering applications [22]. On one hand, there are 
several studies addressing the fatigue behaviour of $100 \%$ plant fibre composites or $100 \%$ basalt fibre composites. For example, Bensadoun et al. [23] compared the tension-tension fatigue behaviour of flax fibre composites for nine different reinforcement architectures combined with epoxy matrix: one random mat, two cross-ply laminate configurations and six textiles (a plain weave, three twills with various twist values, a quasi-unidirectional and a unidirectional fabrics). They showed that composites displaying high static strength have longer fatigue lifetimes, even if, as the loading level decreases, all textile and cross-ply laminates achieve comparable lifetimes. In their review, Mahboob and Bougherara [24] reported that fatigue testing parameters (e.g. frequency, loading ratio) and structural variables (e.g. off-axis plies, moisture content, fibre crimp, 'out-of-plane' weaves in fabric) are all influencing longevity of plant fibre composites. Regarding the moisture content, Barbiere et al. [25] have recently demonstrated the influence of the storage and the testing conditions on fatigue behaviour of a woven hemp/epoxy composite. Liang et al. [26], in their study, showed that the $[ \pm 45]_{3 \mathrm{~S}}$ flax/epoxy specimens offer better specific fatigue endurance than similar glass/epoxy laminates, which was not the case for the [0/90]3s specimens. On the opposite, for basalt/epoxy composites, Dorigato et al. [27] found superior performances of basalt/epoxy laminates with respect to the corresponding glass/epoxy composites, with an improved capability of sustaining progressive damaging and slightly higher damping properties. Zhao et al. and Wang et al. $[28,29]$ have also demonstrated the fatigue performances of basalt/epoxy composites. In particular, Wang et al. [29] compared the fatigue behaviour of basalt composites with thermosetting or thermoplastic epoxy matrix and observed that the basalt fibre-reinforced thermosetting epoxy polymer composite has similar static strength and similar fatigue life at high-stress levels than the thermoplastic epoxy-based one. However, at lowstress levels, the fatigue life for the latter is much higher than that of thermosetting epoxy-based one. On the other hand, there are only few studies on the fatigue behaviour of hybrid composites with continuous reinforcements. Sharba et al. carried out a study on the effect of kenaf fibre orientation on fatigue life of a glass-kenaf hybrid composite [30]. Mostafa performed fatigue tests on glass-jute hybrid composites [31], Sivakumar et al. studied glass-kenaf hybrid composites [32] and Salman et al. worked on Kevlar-kenaf hybrid composites [33]. The benefits of basalt hybridisation in flax based 
laminates have been well documented in literature in terms of quasi-static [34-36] and low velocity impact properties [37, 38]. Nevertheless, to the best of authors' knowledge, there are no published results concerning the fatigue behaviour of basalt-plant hybrid composites. The aim of the current study is to bridge this gap. Basalt and flax fibres are chosen for their eco-friendly character along with their good mechanical performances. With a view to semi-structural applications, for example in the transport sector, woven reinforcement is selected, being also better suited to resist accidental impact events. At first, an optimisation of the curing cycle was made in order to reach the highest possible value of the glass transition temperature for the epoxy resin. Then, three different kinds of woven composites were manufactured: two non-hybrid composites with only flax reinforcement or basalt reinforcement, and a basalt-flax hybrid composite. Quasi-static tensile tests and tension-tension fatigue tests were performed on samples with two orientations, $0^{\circ} / 90^{\circ}$ and $\pm 45^{\circ}$. The application of a fatigue life model is proposed, while damage mechanisms are investigated by means of infrared thermography and scanning electron microscopy.

\section{Materials and methods}

\subsection{Materials}

Concerning the plant reinforcement, a Biotex flax fabric (Linum usitatissimum), supplied by Composites Evolution (UK), was used. This fabric is commercialised without any specific sizing. It is a $2 \times 2$ twill fabric with a fibre areal weight of $200 \mathrm{~g} / \mathrm{m}^{2}$. Each flax yarn has a diameter of about $327 \mu \mathrm{m}$ and is made of several elementary flax fibres twisted together. A typical elementary flax fibre has a diameter of about $25 \mu \mathrm{m}$ [39]. For the mineral reinforcement, a basalt woven fabric, supplied by Basaltex (Belgium), was selected. It is a plain woven fabric $\left(220 \mathrm{~g} / \mathrm{m}^{2}\right)$, made of $100 \%$ BCF (basalt continuous filament) roving. One basalt fibre has a nominal diameter of $13 \mu \mathrm{m}$ [40]. For all the composites, the same epoxy resin was used. It is the PRIME 27 infusion resin with the PRIME 20 slow hardener, both delivered by GURIT. The mixing ratio was 100:28 by weight.

Three kinds of epoxy matrix woven composites were manufactured, all with the same target thickness: $2.5 \pm 0.3 \mathrm{~mm}$. Two non-hybrid composites were elaborated as reference materials: a flax composite 
(100\% flax), made of 4 plies, and a basalt composite (100\% basalt), made of 16 plies. The hybrid composite (50\% of flax plies and $50 \%$ of basalt plies) consisted of 8 plies with a symmetrical intercalated sequence: $\left[(\text { basalt/flax })_{2}\right]_{\mathrm{s}}$. This stacking sequence has been chosen because optimum mechanical properties can be achieved by placing high strength fibres as the skin layers [41]. For instance, Gupta et al. have compared the mechanical properties of flax fibre composite, glass fibre composite, glass-flax-glass hybrid (GFGH) composite and flax-glass-flax hybrid (FGFH) composite. They reported that the stacking sequence GFGH was superior to the FGFH one in terms of tensile, compressive, flexural and impact strengths [42].

The different composite plates were produced by vacuum infusion. The fabrication process started with cleaning the mould plate and waxing it with a release agent so that proper demoulding can be achieved after curing. Then the dry plies were stacked on the mould plate to make the proper laminates. Peel ply, sealing tape and resin tubing were added and the whole set up was vacuum bagged. Then the resin was infused and impregnated the fabrics. The fibre volume fraction $V_{f}$ and the porosity volume fraction $V_{p}$ were determined for each type of composite by weighing and measuring samples. For the basalt composite, $V_{f}$ is equal to $55 \pm 1 \%$, and it is $26 \pm 0.6 \%$ for the flax one. The fibre volume fraction is $33 \pm 0.7 \%$ for the flax-basalt hybrid composite, with $20 \%$ of flax fibres and $13 \%$ of basalt fibres. The average measured value of $V_{p}$ for all the tested samples is $7.5 \pm 2 \%$. In order to assess the influence of fibre orientation on the mechanical properties of the composites, specimens were cut in two different directions in the manufactured plates. Thus, two stacking sequences were studied: a first sequence, identified as $0^{\circ} / 90^{\circ}$, is characterised by the warp yarns aligned along the loading direction; the second sequence, identified as $\pm 45^{\circ}$, corresponds to an orientation of the warp yarns at 45 degrees with respect to the loading direction of the composite. Each sample has a rectangular shape with an overall length of $150 \mathrm{~mm}$, a gauge length of $60 \mathrm{~mm}$ and a width of $25 \mathrm{~mm}$.

In order to produce a valid failure mode during fatigue tests, i.e. within the gauge length of the specimens, different tab configurations were tried, with various materials (aluminium, glass/PP composite and glass/epoxy composite) and geometries. A final configuration of glass/epoxy tabs with 
a length of $40.5 \mathrm{~mm}$, a thickness of $1.3 \mathrm{~mm}$ and a taper angle of $15^{\circ}$ was chosen. The ADEKIT H9951 structural epoxy adhesive, supplied by Axon, was used for the tab bonding (Fig. 1).

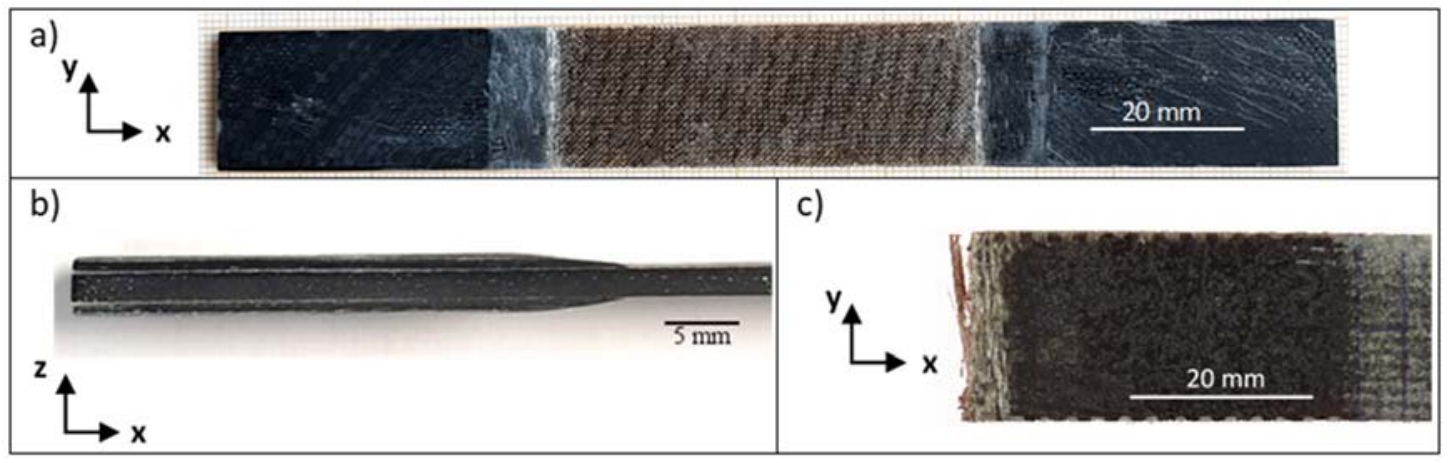

Fig. 1. a) a $0^{\circ} / 90^{\circ}$ flax composite sample before testing, b) the glass/epoxy tabs bonded on a $\pm 45^{\circ}$ flax-basalt composite sample, c) a $0^{\circ} / 90^{\circ}$ basalt composite sample after tensile failure.

\subsection{Differential Scanning Calorimetry (DSC) measurements}

DSC measurements were performed using the differential scanning calorimeter Q20 from $T A$ Instruments on pure resin samples. For each test, two aluminium pans were prepared: the first one is empty and is used as the reference and the second one is filled with the matrix sample (between $5 \mathrm{mg}$ and $10 \mathrm{mg}$ of material were used). The method used was as follows: a first heating cycle from $20^{\circ} \mathrm{C}$ to $150{ }^{\circ} \mathrm{C}$, an isotherm of 2 minutes at $150{ }^{\circ} \mathrm{C}$, a cooling cycle from $150{ }^{\circ} \mathrm{C}$ to $20^{\circ} \mathrm{C}$, an isotherm of 2 minutes at $20^{\circ} \mathrm{C}$ and finally a second heating cycle identical to the previous one. All heating cycles were carried out with a rate of $10^{\circ} \mathrm{C} / \mathrm{min}$.

\subsection{Tensile testing}

A tensile characterisation of the basalt/epoxy, flax/epoxy and basalt-flax/epoxy composite materials was carried out by performing tests at room temperature (ASTM D 3039). An Instron 1195 machine equipped with a $100 \mathrm{kN}$ load cell and with manual wedge action grips was used. For each test, a crosshead speed of $2.5 \mathrm{~mm} / \mathrm{min}$ was used and the sample deformation was evaluated using an axial clip-on extensometer. 


\subsection{Fatigue testing}

Fatigue tests were performed using an Instron 8874 servo-hydraulic bi-axial testing machine equipped with a $25 \mathrm{kN}$ load cell and screw grips (Fig. 2). Tests were realised according to the ASTM D 3479 standard test method. Constant amplitude loads were applied in a sinusoidal waveform at a frequency of $5 \mathrm{~Hz}$ under load-control. Tension-tension mode fatigue tests were carried out with a stress ratio $(R)$ of 0.1 . Fatigue tests were performed on the three composites for both $0^{\circ} / 90^{\circ}$ and $\pm 45^{\circ}$ orientations.

Different levels of maximum stress $\sigma_{\max }$ were used, from $25 \%$ to $85 \%$ of the tensile strength $\sigma_{f}$. Some samples were not broken after more than $3 \times 10^{6}$ cycles. In that cases, fatigue tests were stopped and are indicated with an arrow in S-N curves.

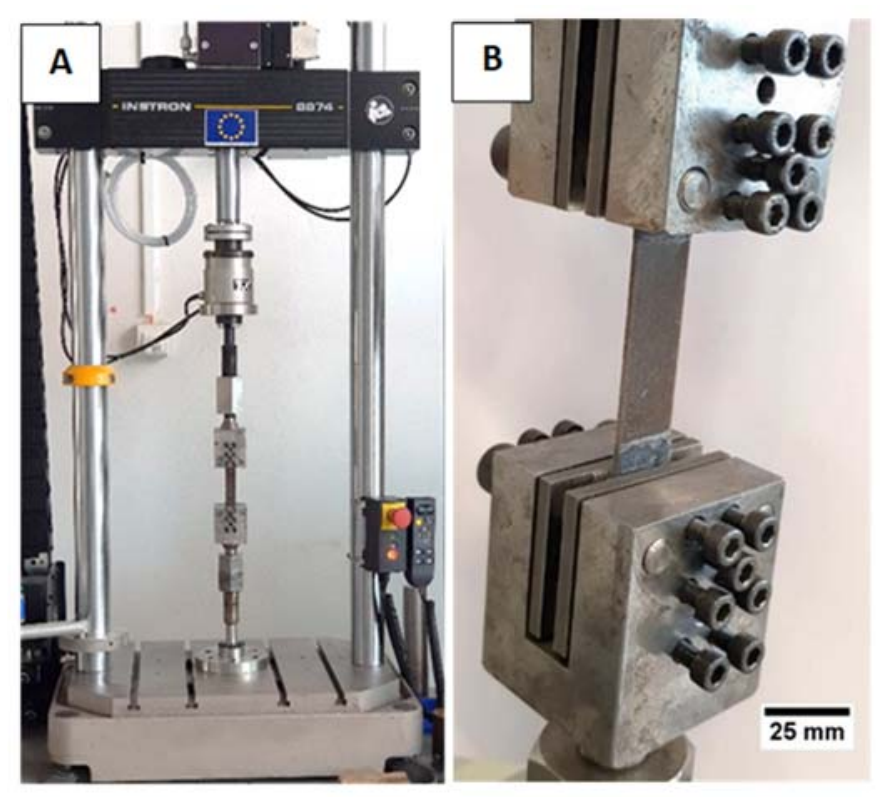

Fig. 2. The fatigue testing machine (A) and the grips configuration used (B).

\subsection{Infrared camera}

A qualitative analysis of the temperature evolution at the specimen surface was performed by a Fluke Ti $300^{+}$Thermal Camera, with an acquisition rate of $9 \mathrm{~Hz}$. This camera is equipped with the LaserSharp ${ }^{\mathrm{TM}}$ AutoFocus, ensuring focused images. The temperature range is $-20{ }^{\circ} \mathrm{C}$ to $650{ }^{\circ} \mathrm{C}$ with a measurement accuracy of $\pm 2{ }^{\circ} \mathrm{C}$ at $25^{\circ} \mathrm{C}$ and a detector resolution of $320 \times 240$ pixels.

\subsection{FE-SEM observations}


After fatigue tests, the morphology of the fracture surfaces of the different composites was investigated by a Field Emission - Scanning Electron Microscope (FE-SEM): JEOL JSM-7000F. All specimens were sputter coated with gold prior to FE-SEM observation.

\section{Results and discussion}

\subsection{Optimisation of the curing cycle}

In order to reach the maximum level of crosslinking for the epoxy resin and thus to generate optimal mechanical properties of the resin, an optimisation of the curing process was carried out. The glass transition temperatures, $\mathrm{T}_{\mathrm{g}}$, were determined by DSC measurements on various epoxy samples. Fig. 3 shows an example of DSC thermogram obtained with an uncured epoxy sample. The endothermic peak visible at about $50{ }^{\circ} \mathrm{C}$ during the first heating cycle can be referred to as the physical aging phenomenon of the resin. Indeed, the storage of polymers below their glass transition temperature results in a gradual process of molecular relaxation in which the polymer chains form denser regions. This endothermic peak is thus due to the enthalpic recovery of the polymer. It demonstrates that the $\mathrm{T}_{\mathrm{g}}$ value for the uncured resin is about $50^{\circ} \mathrm{C}$.

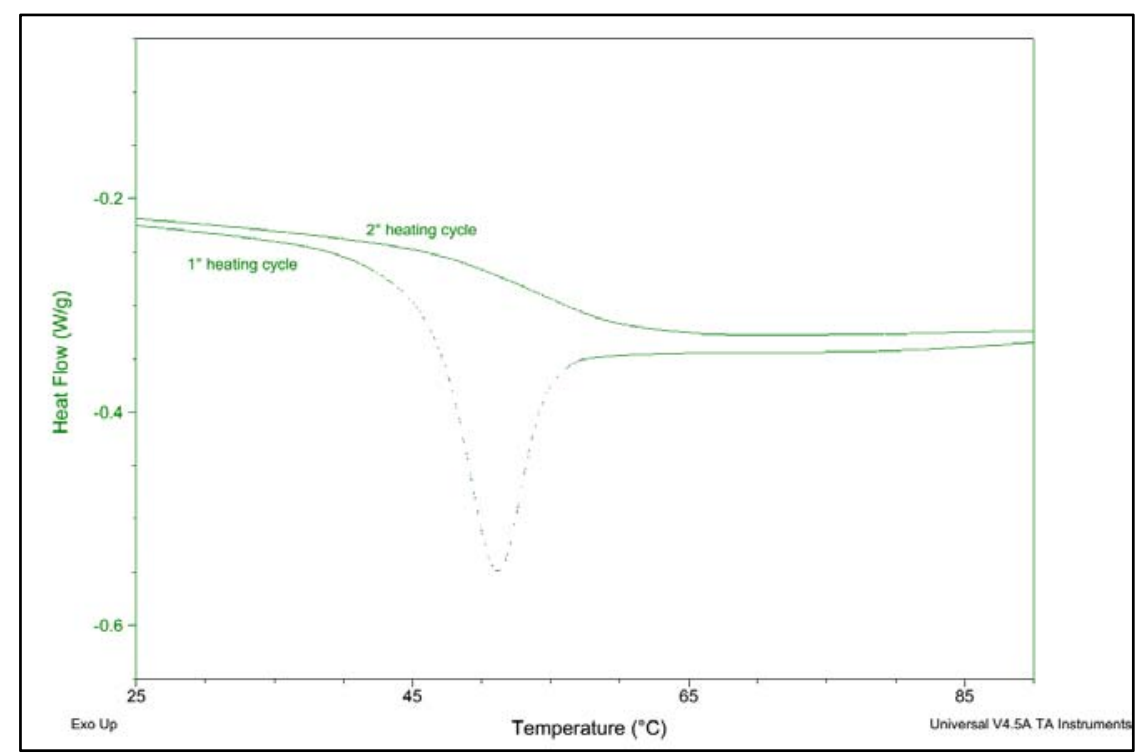

Fig. 3. DSC thermogram of the uncured epoxy resin. Two curing protocols were then tested: one with a duration of 16 hours at $50{ }^{\circ} \mathrm{C}$ and one with a duration of 7 hours at $65^{\circ} \mathrm{C}$. 
From the DSC results shown in Fig. 4, it is possible to see that, although such curing treatments are suggested in the technical data sheet of the manufacturer, the presence of an exothermic phenomenon in both DSC curves during the first heating cycle (red arrows in Fig. 4) indicates that such curing schedules are not sufficient to complete the resin crosslinking and thus to maximise its mechanical properties.

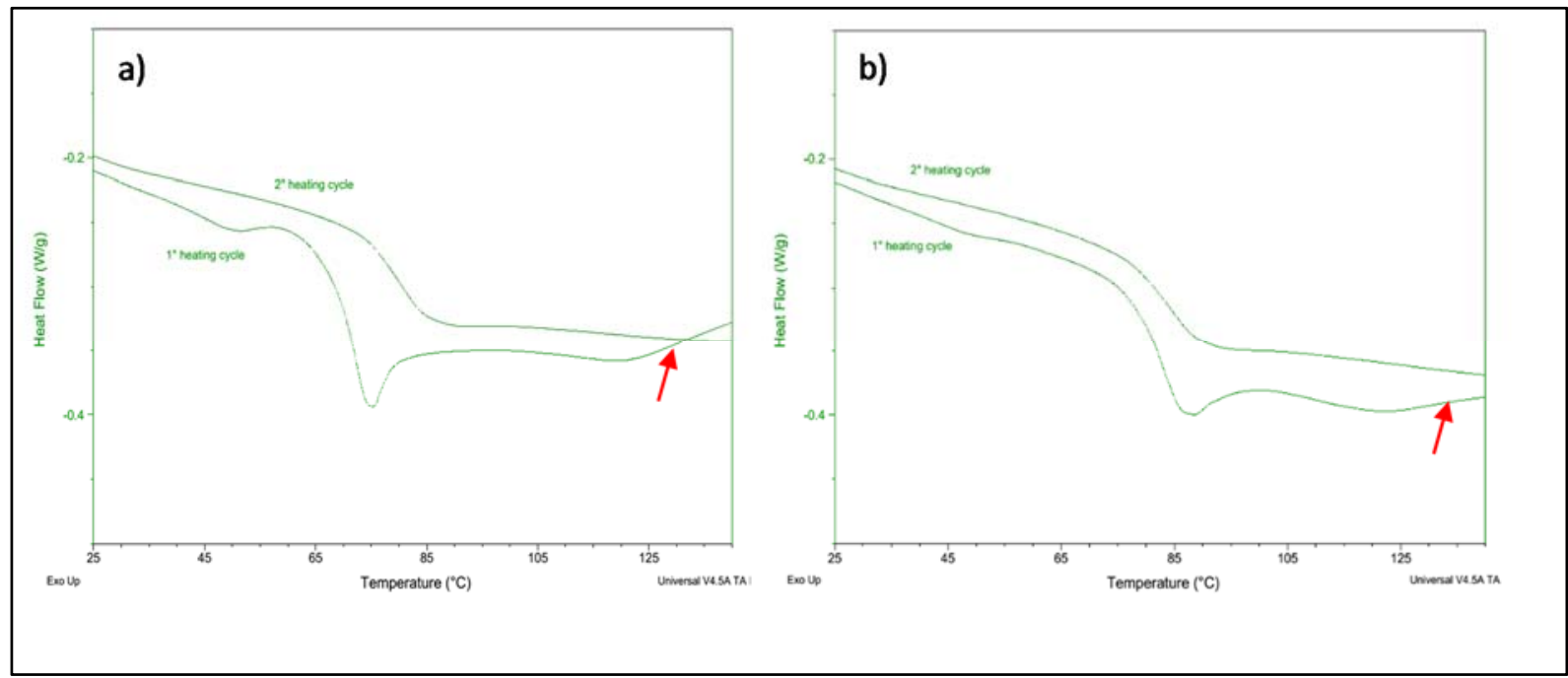

Fig. 4. DSC thermograms for the epoxy resin after the curing process at $50{ }^{\circ} \mathrm{C}$ during 16 hours (a), and at $65{ }^{\circ} \mathrm{C}$ during 7 hours (b).

Therefore, other curing protocols were investigated. Finally, the curing process with a duration of 7 hours at $90{ }^{\circ} \mathrm{C}$ was selected. It can be seen in Fig. 5 that, after this curing process, the exothermic phenomenon is completely eliminated from DSC curves and so the crosslinking of the resin can be considered almost complete. This curing treatment leads to a $\mathrm{T}_{\mathrm{g}}$ of about $88.9^{\circ} \mathrm{C}$. All the composite plates were thus cured with this procedure of $7 \mathrm{~h}$ at $90{ }^{\circ} \mathrm{C}$. 


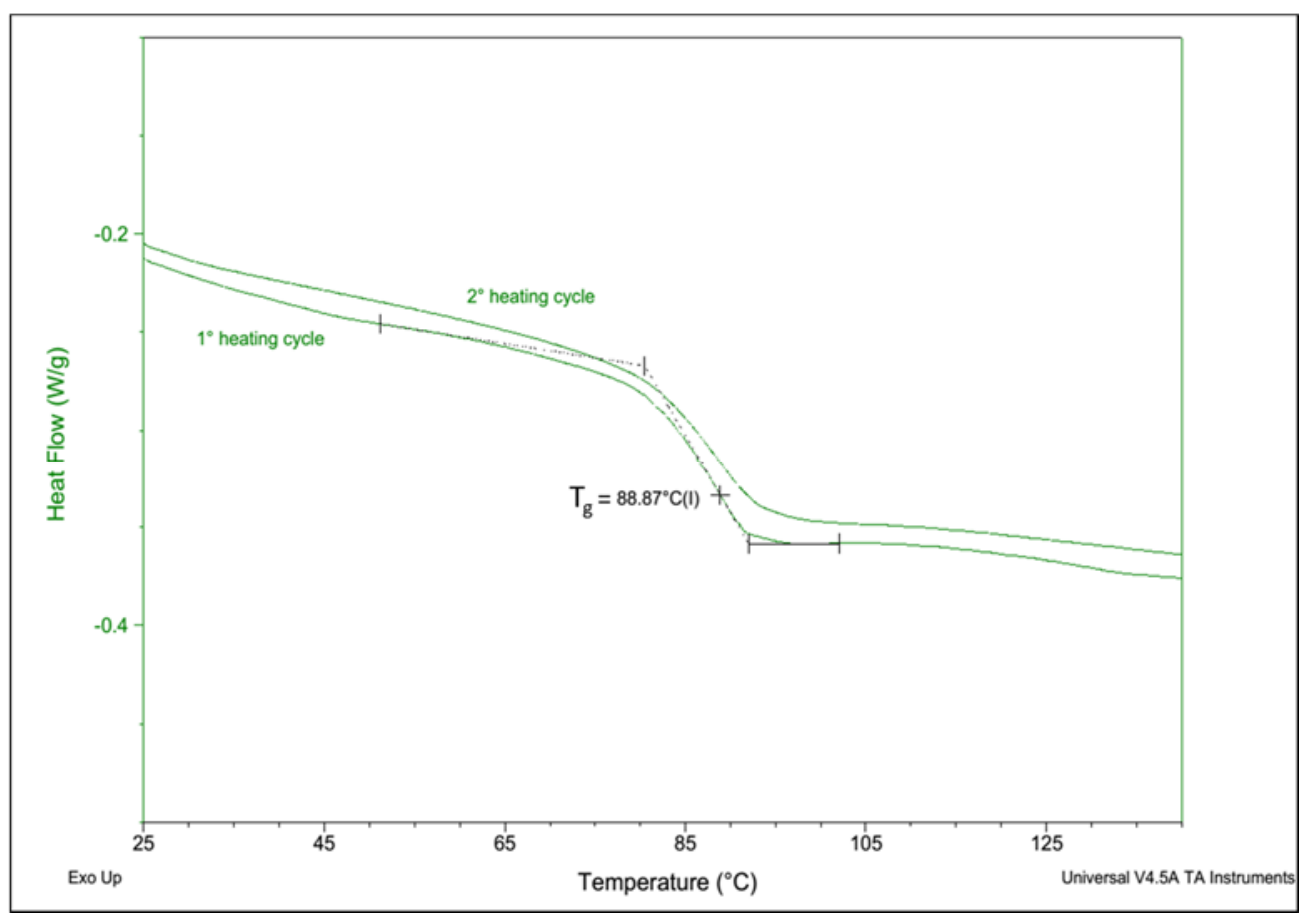

Fig. 5. DSC thermograms for the epoxy resin after the curing treatment at $90{ }^{\circ} \mathrm{C}$ during 7 hours.

\subsection{Tensile characteristics}


Quasi-static tensile tests were carried out on a minimum of three specimens for each type of composite: basalt, flax and flax-basalt hybrid materials with the two orientations, $0^{\circ} / 90^{\circ}$ and $\pm 45^{\circ}$. Examples of stress-strain curves obtained for $0^{\circ} / 90^{\circ}$ and $\pm 45^{\circ}$ flax-basalt hybrid composites are plotted in Fig. 6 . For the $0^{\circ} / 90^{\circ}$ orientation, the tensile curve is quasi linear up to failure, driven by the behaviour of longitudinal fibres. On the contrary, for the $\pm 45^{\circ}$ orientation, the matrix-dominated behaviour leads to a more ductile aspect of the curve (Fig. 6). The mean values of tensile strengths and moduli for all the tested composites are given in Table 1.

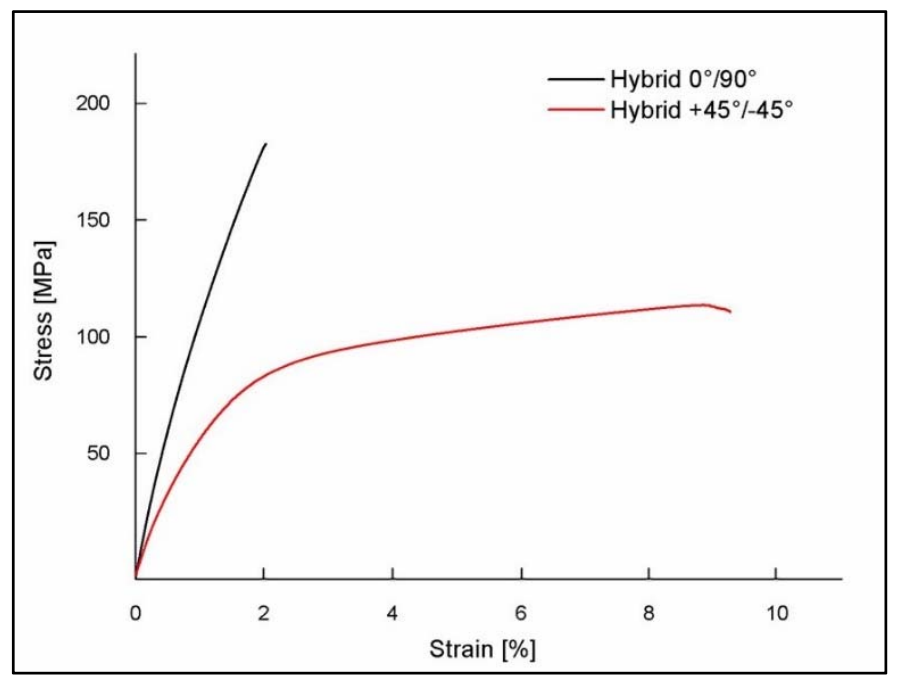

Fig. 6. Examples of quasi-static tensile stress-strain curves for the $0^{\circ} / 90^{\circ}$ and the $\pm 45^{\circ}$ flax-basalt hybrid composites.

For $100 \%$ flax composite, in literature, Bensadoun et al. [23] obtained a tensile strength of $120 \mathrm{MPa}$ and a modulus of $12.8 \mathrm{GPa}$ for a $0 / 90$ twill flax/epoxy composite with a fibre volume fraction of $40 \%$. The results of the present study are consistent with these values, as for a fibre volume fraction of 26 $\%$, the tensile strength is $106 \mathrm{MPa}$ and the elastic modulus is $6 \mathrm{GPa}$ for the $0^{\circ} / 90^{\circ}$ orientation (Table 1). For the $100 \%$ basalt composite, measured values are similar to those obtained by Dorigato et al. [27] for a fibre volume fraction of $61 \%$, while it is of $55 \%$ in the present study: $600 \mathrm{MPa}$ vs $635 \mathrm{MPa}$ for the tensile strength, and $29.6 \mathrm{GPa}$ vs. $28.8 \mathrm{GPa}$ for the Young's modulus of the $0^{\circ} / 90^{\circ}$ orientation. 
Table 1. Tensile strengths and moduli of the hybrid and non-hybrid composite materials for the two orientations.

\begin{tabular}{cccc}
\hline Orientation & Material & $\sigma_{\mathbf{f}}[\mathbf{M P a}]$ & E [GPa] \\
\hline & Basalt & $635 \pm 50$ & $28.8 \pm 0.2$ \\
$0^{\circ} / 90^{\circ}$ & Flax & $106.3 \pm 5.2$ & $5.8 \pm 0.1$ \\
& Flax-basalt hybrid & $190.9 \pm 6.4$ & $13.2 \pm 0.1$ \\
\hline \multirow{4}{*}{ Basalt } & $154.3 \pm 5.4$ & $14.6 \pm 0.5$ \\
& Flax & $63.6 \pm 0.6$ & $3.7 \pm 0.1$ \\
& Flax-basalt hybrid & $118.4 \pm 1.7$ & $6.8 \pm 0.8$ \\
\hline
\end{tabular}

Results in Table 1 also show that, for $0^{\circ} / 90^{\circ}$ and $\pm 45^{\circ}$ orientations, the flax fibre composites exhibit a significantly lower tensile strength $\sigma_{f}$ and elastic modulus $E$ than the basalt composites, while the hybrid composites show an intermediate behaviour (Table 1). This is in accordance with the results obtained in tensile loading for carbon-natural fibres hybrid composites [43] or for jute-glass hybrid composites [31].

\subsection{Wöhler curves}

Fatigue tests were performed on each type of composite: basalt, flax and flax-basalt hybrid materials for the two orientations $0^{\circ} / 90^{\circ}$ and $\pm 45^{\circ}$. Between eight and twelve samples were tested for each configuration, with two or three tests for given stress levels. The average number of fatigue failure cycles is given in Table 2 for the $0^{\circ} / 90^{\circ}$ orientation, and in Table 3 for the $\pm 45^{\circ}$ one. 
Table 2. The average number of fatigue failure cycles for hybrid and non-hybrid $0^{\circ} / 90^{\circ}$ composites.

\begin{tabular}{|c|c|c|c|}
\hline \multirow[b]{2}{*}{$\sigma_{\max }$} & \multicolumn{3}{|c|}{$\mathbf{N}_{\mathrm{f}}$} \\
\hline & Basalt & Flax & $\begin{array}{c}\text { Flax-basalt } \\
\text { hybrid }\end{array}$ \\
\hline $85 \% \sigma_{f, 0^{\circ}}$ & 73 & 17 & 167 \\
\hline $65 \% \sigma_{f, 0^{\circ}}$ & 231 & 3165 & 3214 \\
\hline $45 \% \sigma_{f, 0^{\circ}}$ & 804 & 69480 & 16167 \\
\hline $35 \% \sigma_{f, 0^{\circ}}$ & 8001 & 1097894 & 330527 \\
\hline $30 \% \sigma_{\mathrm{f}, 0^{\circ}}$ & 69965 & / & / \\
\hline $25 \% \sigma_{\mathrm{f}, 0^{\circ}}$ & 2852941 & $>3145098$ & $>10000000$ \\
\hline
\end{tabular}

Table 3. The average number of fatigue failure cycles for hybrid and non-hybrid $\pm 45^{\circ}$ composites.

\begin{tabular}{|c|c|c|c|}
\hline \multirow{3}{*}{$\sigma_{\max }$} & \multicolumn{3}{|c|}{$\mathbf{N}_{\mathrm{f}}$} \\
\hline & \multirow[b]{2}{*}{ Basalt } & \multirow[b]{2}{*}{ Flax } & Flax-basalt \\
\hline & & & hybrid \\
\hline $85 \% \sigma_{f, 45^{\circ}}$ & 106 & 2370 & 210 \\
\hline $65 \% \sigma_{f, 45^{\circ}}$ & 382 & 21690 & 1541 \\
\hline $50 \% \sigma_{f, 45^{\circ}}$ & 1010 & 813931 & 57596 \\
\hline $45 \% \sigma_{f, 45^{\circ}}$ & 7014 & 1535002 & 268131 \\
\hline $35 \% \sigma_{f, 45^{\circ}}$ & 2924442 & $>3933076$ & 2832228 \\
\hline
\end{tabular}

The corresponding Wöhler curves are plotted in Fig. 7. The points related to the non-broken samples are indicated by an arrow. It can be seen in Fig. 7 that there is a slight and usual dispersion in fatigue lifetime for all the tested materials. As expected, for a given number of fatigue failure cycles, the maximum stress is lower for flax composites than for basalt composites, and intermediate for flax- 
basalt composites, in accordance with the quasi-static tensile strengths (Table 1). Moreover, fatigue results demonstrate that, for each type of composite, for a given maximum fatigue stress value, the fatigue life for the $\pm 45^{\circ}$ orientation is far lower than for the $0^{\circ} / 90^{\circ}$ one.

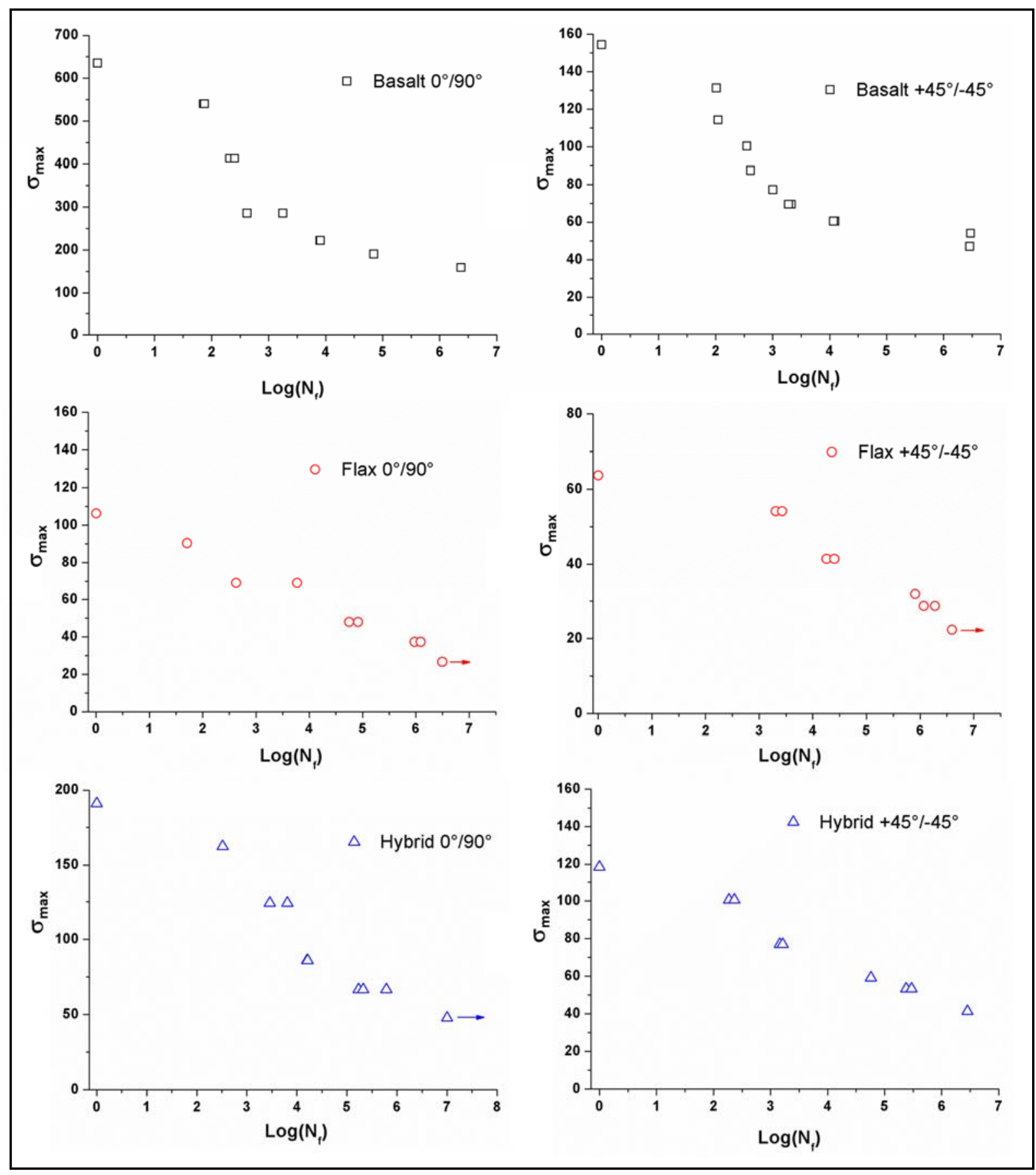

Fig. 7. Wöhler curves for basalt, flax and hybrid composites with $0^{\circ} / 90^{\circ}$ and $\pm 45^{\circ}$ orientations. 
In order to compare the fatigue sensitivity of the different materials, normalised Wöhler curves are reported in Fig. 8 and Fig. 9 for the $0^{\circ} / 90^{\circ}$ and $\pm 45^{\circ}$ orientations, respectively. In these figures, the $x-$ axis is the decimal logarithm of the number of cycles to failure for each sample, while the y-axis reports the ratio between the maximum applied stress and the tensile strength. The points related to the non-broken samples are again indicated by an arrow.

The main aspect emerging from Fig. 8 and 9 is the positive effect of hybridisation when comparing the normalised S-N curves for these different composites. For both $0^{\circ} / 90^{\circ}$ and $\pm 45^{\circ}$ orientations, the hybrid composites exhibit an intermediate fatigue behaviour between those of basalt/epoxy and flax/epoxy composites. The fatigue resistance of basalt/epoxy composites is enhanced by flax fibre hybridisation. From Fig. 8 and 9 it is possible to point out that the hybridisation allows to obtain a higher number of cycles to failure than those of basalt fibre reinforced composites. This result may be related to a positive action of flax fibres. Several studies present in literature have compared the fatigue behaviour of natural fibre reinforced composites with that of glass fibre composites. Most of these works highlighted that the glass reinforced composites display a higher absolute resistance to fatigue than the natural fibre reinforced composites [24]. This is mainly due to the superior tensile strength of glass fibre composites compared to plant fibre composites. Shah et al. [44] performed a comparison between the fatigue behaviour of plant fibre (jute, hemp and flax) polyester matrix composites with the behaviour of a glass/polyester composite. The authors reported that the fatigue strength degradation rates are lower in plant fibre composites than in glass fibre composites. A slower fatigue stiffness degradation of plant fibres compared to that of glass fibres and the ability of plant fibre to absorb and deflect cracks, thanks to their complex microstructure, can be considered as possible explanations of the fatigue behaviour of natural fibre reinforced composites. This better fatigue resistance of natural fibre composites allows the positive effect of hybridisation that is visible in Fig. 8 and 9: by adding flax fibres, hybrid composites show better fatigue resistance than pure basalt composites. Same behaviour was observed for other hybrid composites in the literature. For example, it has been shown that kenaf-glass [30] or jute-glass [31] hybrid composites exhibit lower fatigue strength but higher fatigue resistance than pure glass composites. 


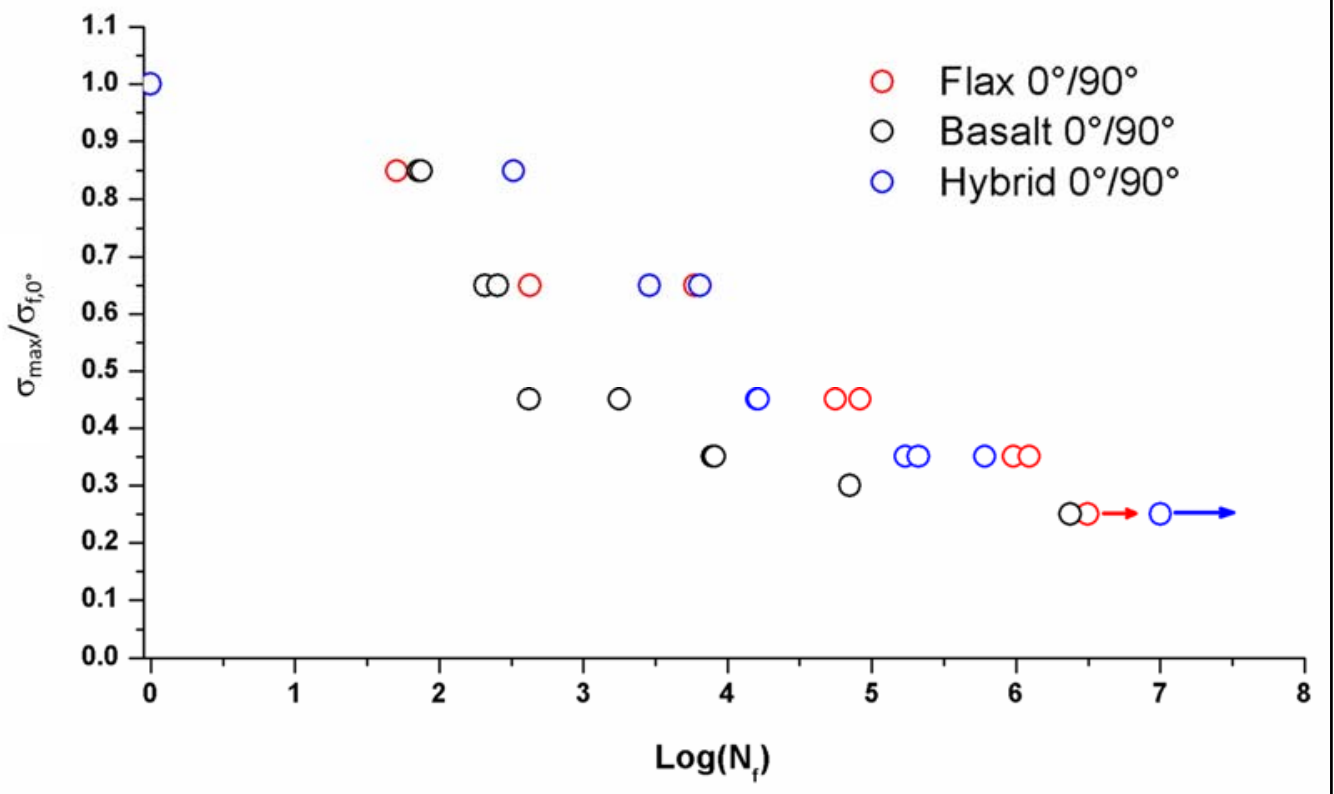

Fig. 8. Normalised Wöhler curves for basalt, flax and hybrid composites with the $0^{\circ} / 90^{\circ}$ orientation.

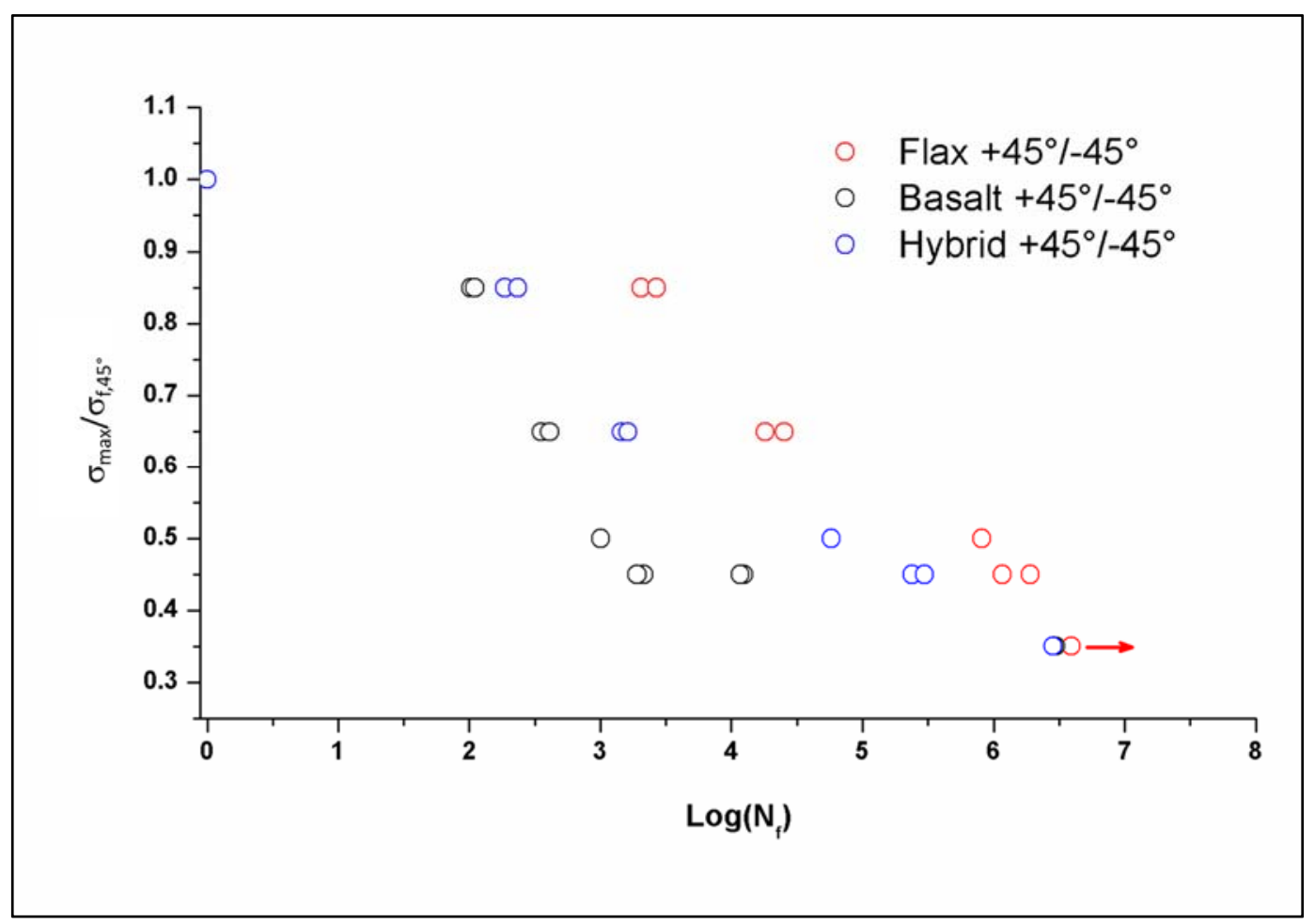

Fig. 9. Normalised Wöhler curves for basalt, flax and hybrid composites with the $\pm 45^{\circ}$ orientation. 


\subsection{Modelling of fatigue life}

Several models have been proposed over the years in order to predict the fatigue resistance of composite materials characterised by different stacking sequences, different types of fibres and matrices and under different loading conditions $[45,46]$. Among these, it is possible to find the model proposed by D'Amore et al., based on the residual strength degradation of the composite [47]. This model was developed for glass-mat-reinforced thermoset based composites, but it was proved to be able to successfully predict the fatigue behaviour of continuous glass fibre reinforced composites [48, 49] and woven hemp/epoxy composites [25]. The model proposed by D'Amore et al. was used as a basis for the development of the Epaarachchi and Clausen model [50], used in the present study. The starting point of the model is a deterministic equation to measure the rate of strength degradation (Eq. 1):

$$
\frac{d \sigma}{d N}=-C_{1} N^{-m_{1}}
$$

where $\sigma$ is the residual strength after $N$ cycles, $C_{l}$ and $m_{l}$ are material constants and $N$ is the number of fatigue cycles. From Eq. 1 and assuming that the fatigue failure occurs when the residual strength remaining in the sample in the direction of applied load is equal to $\sigma_{\max }$, the number of cycles required to degrade the material strength from $\sigma_{f}$ (the ultimate tensile stress) to $\sigma_{\max }$ (the maximum applied stress), corresponding to the number of cycles at failure $N_{f}$, can be expressed using Eq. 2 :

$$
N_{f}=\left[1+\left(\frac{\sigma_{f, \theta}}{\sigma_{\max }}-1\right) \frac{F^{\beta}}{\alpha(1-R)^{1.6-R|\sin \theta|}}\left(\frac{\sigma_{f, \theta}}{\sigma_{\max }}\right)^{0.6-R|\sin \theta|}\right]^{\frac{1}{\beta}}
$$

where $\sigma_{\max }$ is the maximum fatigue stress, $\sigma_{f, \theta}$ is the tensile strength for the orientation $\theta, F$ is the frequency, $R$ is the stress ratio, $\theta$ is the smallest angle of fibres between the loading direction and the fibre direction and $\alpha$ and $\beta$ are the two parameters to be determined. As it can be seen in Eq. 2, this model takes into account the frequency, the stress ratio and the fibre orientation in the composite. In order to identify the two parameters, $\alpha$ and $\beta$, Eq. 2 has to be written as Eq. 3: 


$$
\alpha \cdot\left(N_{f}{ }^{\beta}-1\right)=\left(\frac{\sigma_{f, \theta}}{\sigma_{\max }}-1\right) \frac{F^{\beta}}{(1-R)^{1.6-R|\sin \theta|}}\left(\frac{\sigma_{f, \theta}}{\sigma_{\max }}\right)^{0.6-R|\sin \theta|}
$$

The parameters $\alpha$ and $\beta$ have to be optimised in order to ensure that the experimental data converge on a straight line passing through the origin when plotting the right-hand term against $N_{f}^{\beta}-1$. The optimisation scheme used is described in Fig. 10. The $\alpha$ and $\beta$ values determined for the different composites are reported in Table 4 .

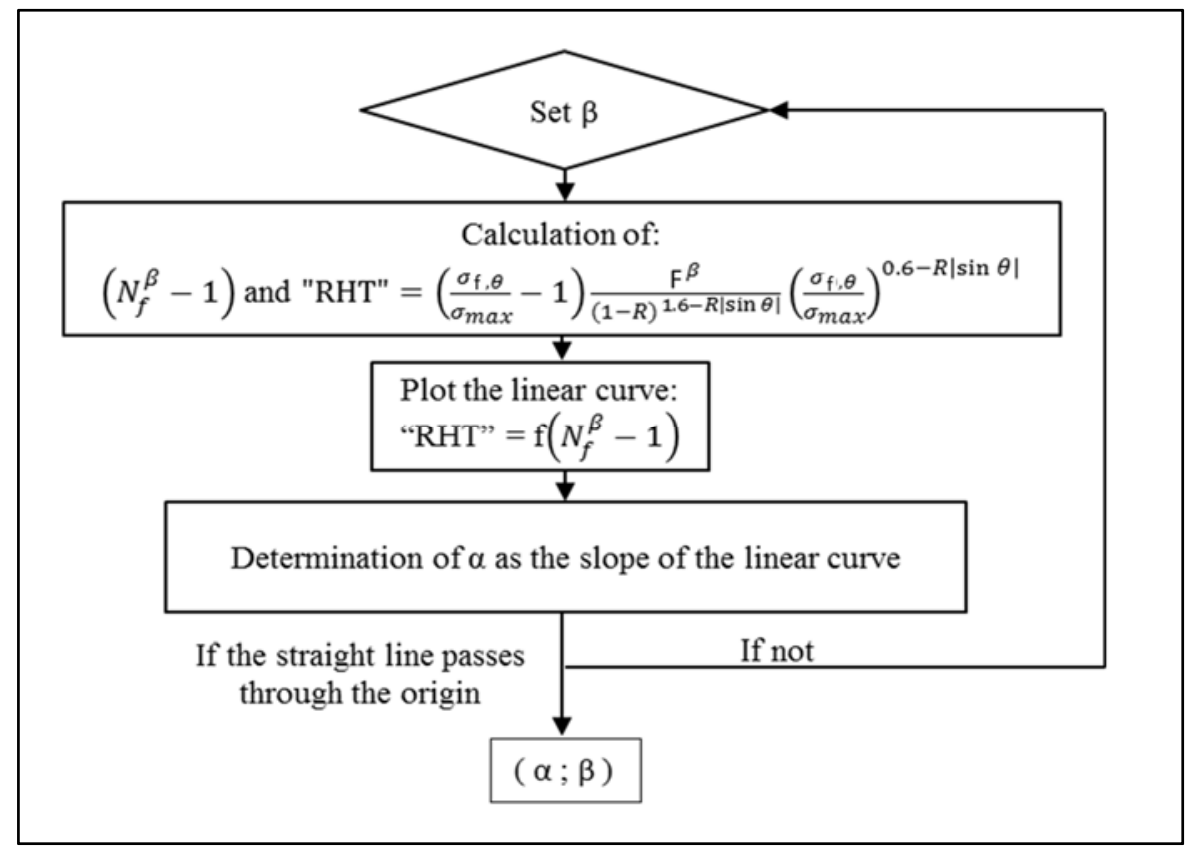

Fig. 10. Optimisation scheme for the determination of $\alpha$ and $\beta$ (from [51]).

Table 4. The $\alpha$ and $\beta$ values of the fatigue life model, calculated for basalt, flax and hybrid composites with $0^{\circ} / 90^{\circ}$ and $\pm 45^{\circ}$ orientations.

\begin{tabular}{cccc}
\hline Orientation & Material & $\boldsymbol{\alpha}$ & $\boldsymbol{\beta}$ \\
\hline \multirow{2}{*}{$0^{\circ} / 90^{\circ}$} & Basalt & 0.129 & 0.473 \\
& Flax & 0.095 & 0.323 \\
& Hybrid & 0.121 & 0.338 \\
\hline \multirow{2}{*}{ $\pm 45^{\circ}$} & Basalt & 0.655 & 0.044 \\
& Flax & 0.043 & 0.320 \\
& Hybrid & 0.245 & 0.210 \\
\hline
\end{tabular}




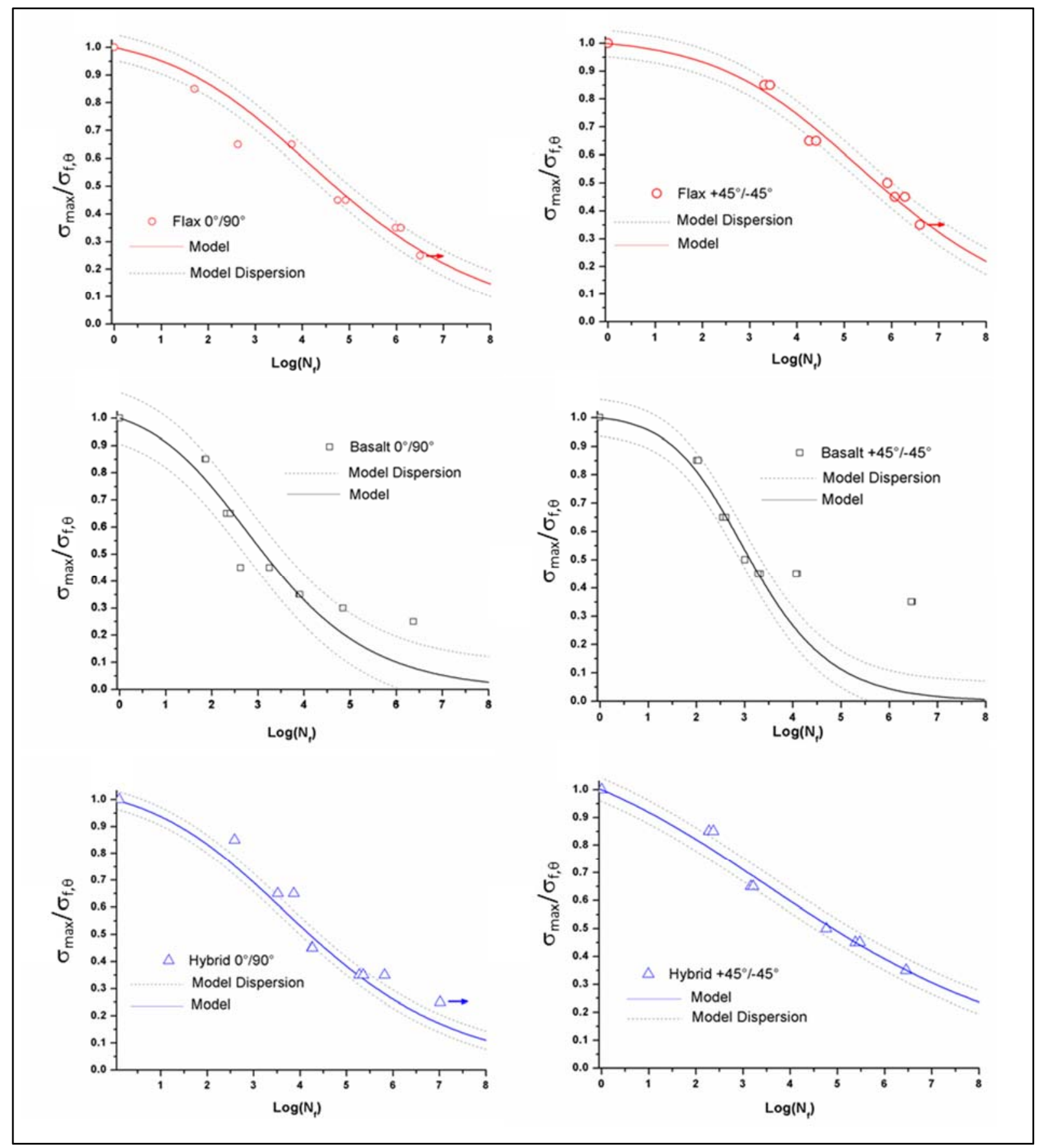

Fig. 11. Normalised Wöhler curves and curves of the Epaarachchi and Clausen model for basalt, flax and hybrid composites with $0^{\circ} / 90^{\circ}$ and $\pm 45^{\circ}$ orientations.

Fig. 11 shows the Wöhler curves of the experimental results for each type of composite and the corresponding Epaarachchi and Clausen model curves, represented by the solid lines. The dashed lines represent the dispersion intervals, which are calculated from the dispersion of the tensile strength.

From Fig. 11 it is possible to observe that the model is able to correctly predict the fatigue behaviour 
of flax fibre and hybrid composites. A good correspondence between the experimental values and the model is reported. On the contrary, a different result is found for the basalt composites for both $0^{\circ} / 90^{\circ}$ and the $\pm 45^{\circ}$ orientations. In particular, the latter configuration exhibits the worst results, specifically at the lower values of maximum applied stress. To better understand this phenomenon and the fatigue behaviour of the different composites, an analysis of the damage was performed.

\subsection{Damage analysis}

A thermal camera has been used in order to obtain the distribution of the temperature on the surface of tested specimens. When a composite is deformed or damaged, a part of the energy is transformed in an irreversible way into heat [52]. In this study, a qualitative analysis of the temperature evolution at the specimens' surface was performed by a thermal camera, with acquisition rate of $9 \mathrm{~Hz}$. Temperature measurements performed on woven hemp/epoxy composites reported that the highest temperature gradient on the specimens' face was obtained for the highest applied fatigue loading values [53]. In addition, the authors highlighted that the temperature gradient is more significant for the $\pm 45^{\circ}$ laminates than for the $0^{\circ} / 90^{\circ}$ ones. For these reasons, in order to address the worst heating conditions, in the present study, measurements were carried out during fatigue tests performed at the stress level of $85 \%$ of the ultimate tensile stress and for the composite samples with the $\pm 45^{\circ}$ orientation. Results show the progressive appearance of hot areas in localised zones on specimen's surface, as shown in Fig. 12, where images were taken right before the specimen's failure. The basalt composite exhibits an excessive overheating, reaching a maximum temperature of $98.5^{\circ} \mathrm{C}$. It demonstrates that, for this configuration, an excessive internal heating occurs during fatigue testing. This phenomenon could explain why the fatigue life model cannot fit with the Wöhler curves obtained for the basalt composites, especially for the $\pm 45^{\circ}$ orientation. Indeed, the model proposed by Epaarachchi and Clausen is based on the assumption that the temperature of the specimen is constant or close to constant during test [50]. 


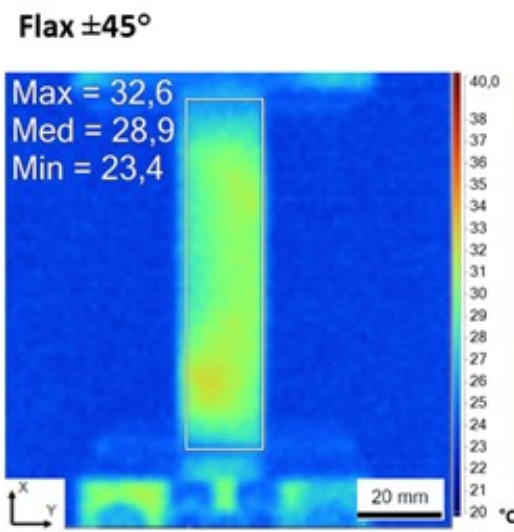

$\mathrm{N}=\mathrm{N}_{\mathrm{f}}-1$
Hybrid $\pm 45^{\circ}$

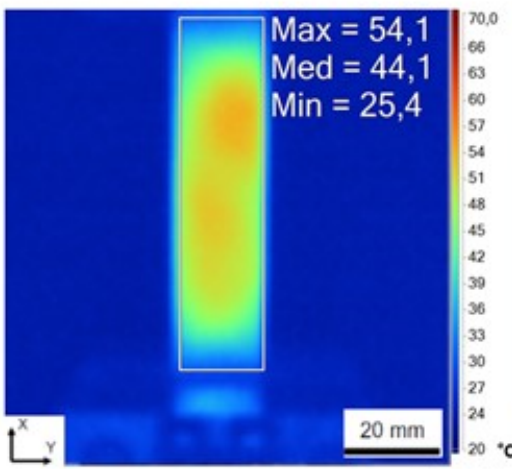

$\mathrm{N}=\mathrm{N}_{\mathrm{f}}-1$
Basalt $\pm 45^{\circ}$

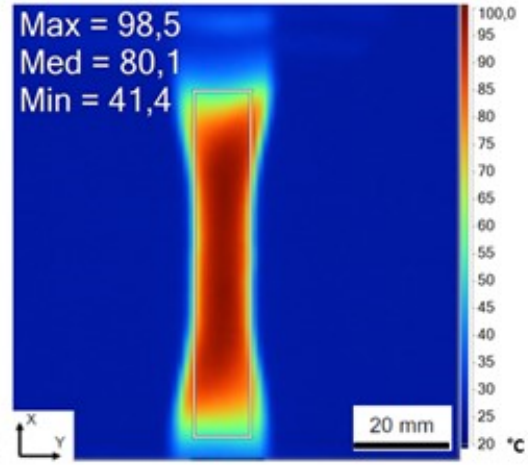

$\mathrm{N}=\mathrm{N}_{f}-1$

Fig. 12. Temperature fields on specimen's surface measured by infrared camera during fatigue tests just before the failure for $\pm 45^{\circ}$ laminates at the stress level of $85 \% \sigma_{f}$.

Post-mortem analysis of failed woven composites was also performed by means of scanning electron microscopy. Fig. 13 to 15 show a morphological analysis of the fracture surfaces of both $0^{\circ} / 90^{\circ}$ and $\pm 45^{\circ}$ laminates for the fatigue stress level of $45 \%$ of the tensile strength for basalt, flax and flax-basalt hybrid composites, respectively. The micrographs show that the main failure modes are the matrix failure (brittle failure), basalt fibre and flax yarn pull-out, fibre failure (transverse failure of the fibre) and fibre or yarn debonding. All the different woven composites exhibit a poor interface quality between the reinforcement and the epoxy matrix. The morphological analysis points out that the interfacial degradation controls the fatigue resistance of all the different laminates. The fracture surfaces for the basalt/epoxy laminates are reported in Fig. 13. Intensive phenomena of basalt fibre pull-out and debonding with the epoxy matrix can be observed in Fig. 13B,D. A strong interface debonding is also found for flax/epoxy composites (Fig. 14). An extensive flax yarn pull-out was observed, where the matrix crack runs around the yarns. Fig. 14B shows a matrix transverse crack spreading around the flax fibre, producing a subsequent debonding at the fibre-matrix interface. Through cyclic loading, the matrix cracks can grow and initiate local debonding between the flax yarns thus causing a faster decrease in resistance of the laminate [23]. In the case of flax fibre composites, where twist and crimp are present compared to the basalt composite counterparts where only the crimp is present, extra matrix cracking can be initiated due to the more complex stress state in 
the twisted yarns oriented along the testing direction. The flax yarns can try to "untwist" creating shear and normal stresses relative to the fibre orientation and resulting in additional micro-cracks at the fibre/matrix interface. The FE-SEM observations also highlighted the presence of porosities, clearly visible in Fig.14A.
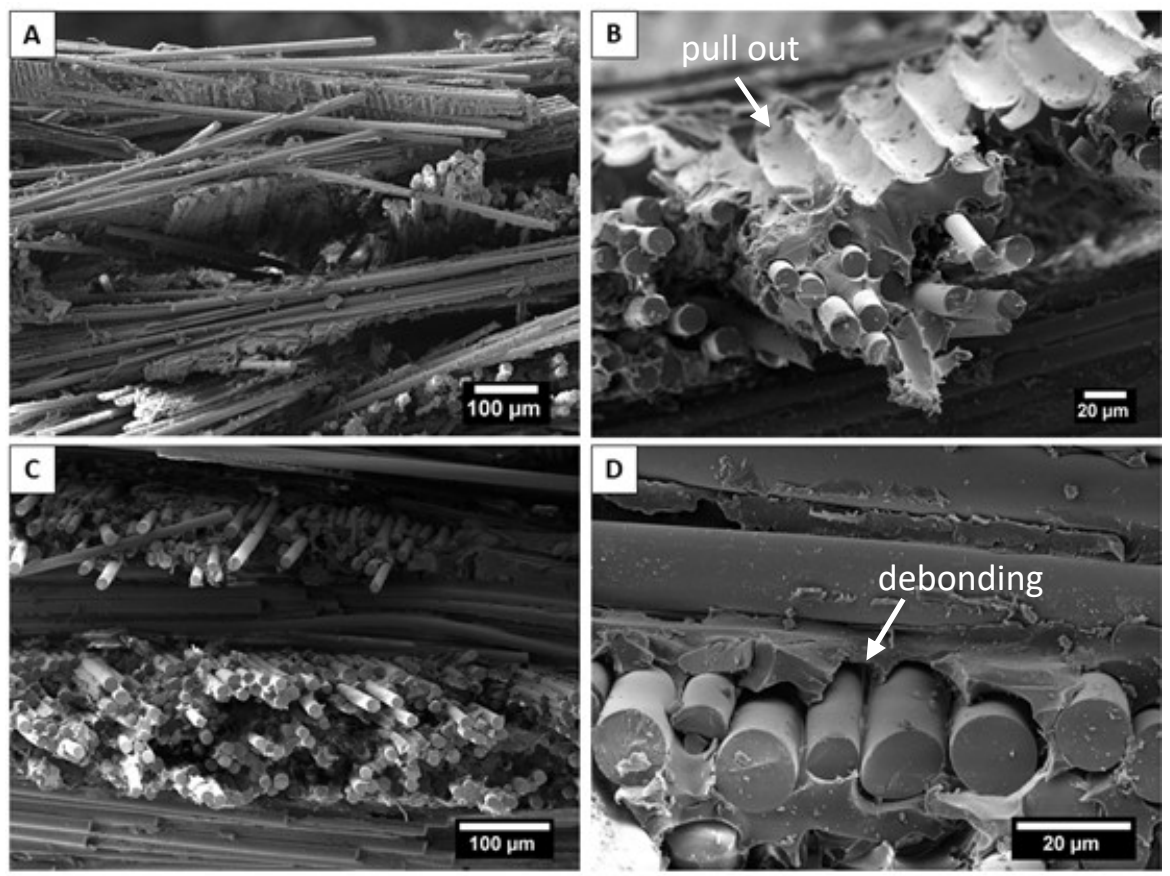

Fig. 13. FE-SEM micrographs of the basalt/epoxy composites after fatigue failure at stress level of 45 $\% \sigma_{f:}$ (A-B) $0^{\circ} / 90^{\circ}$ and $(\mathrm{C}-\mathrm{D}) \pm 45^{\circ}$ laminates.

In hybrid composites, pull-out and debonding phenomena of both basalt fibres and flax yarns can be seen (Fig.15), without evidence of significant delaminations at basalt/flax interfaces. These results show that interfacial adhesion is a key-parameter for fatigue performance of all the composites, hybrids and non-hybrids. 

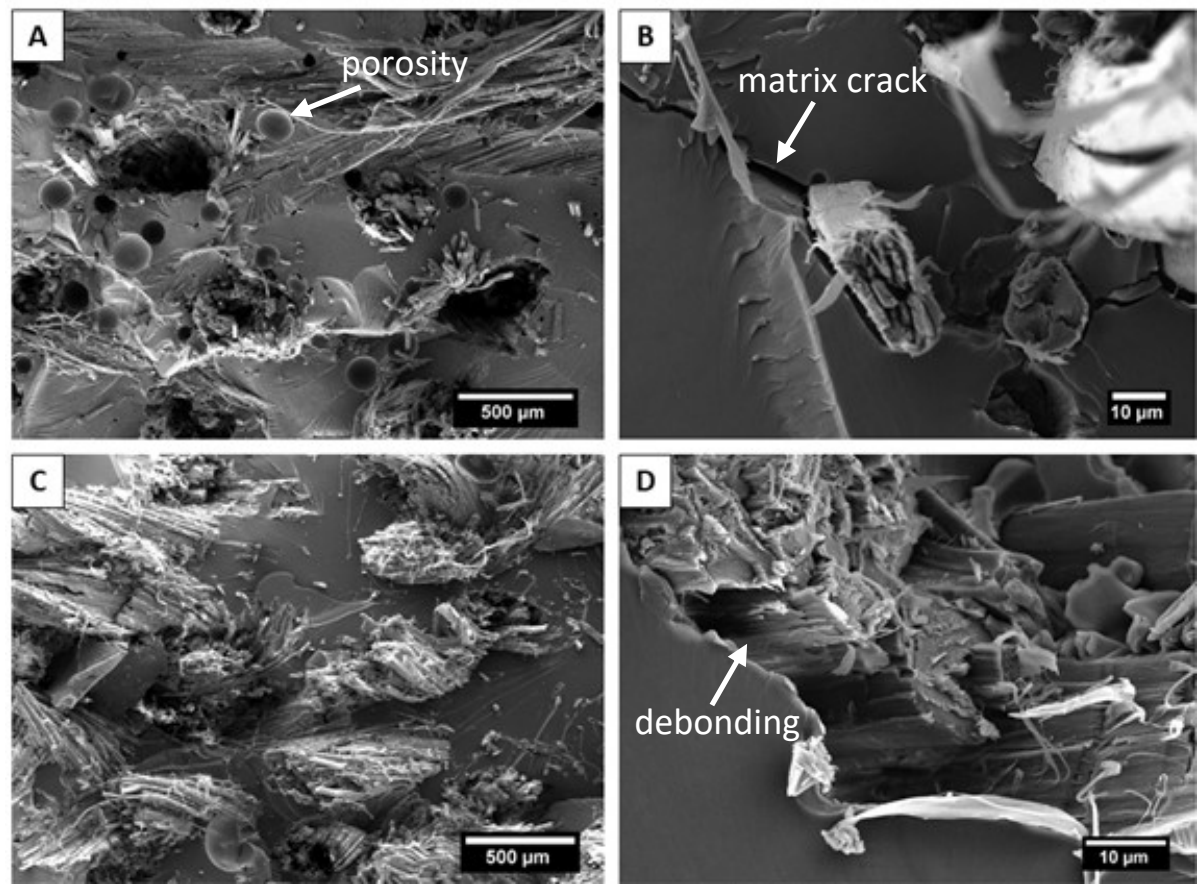

Fig. 14. FE-SEM micrographs of the flax/epoxy composites after fatigue failure at stress level of 45 $\% \sigma_{f}$ : (A-B) $0^{\circ} / 90^{\circ}$ and $(\mathrm{C}-\mathrm{D}) \pm 45^{\circ}$ laminates.
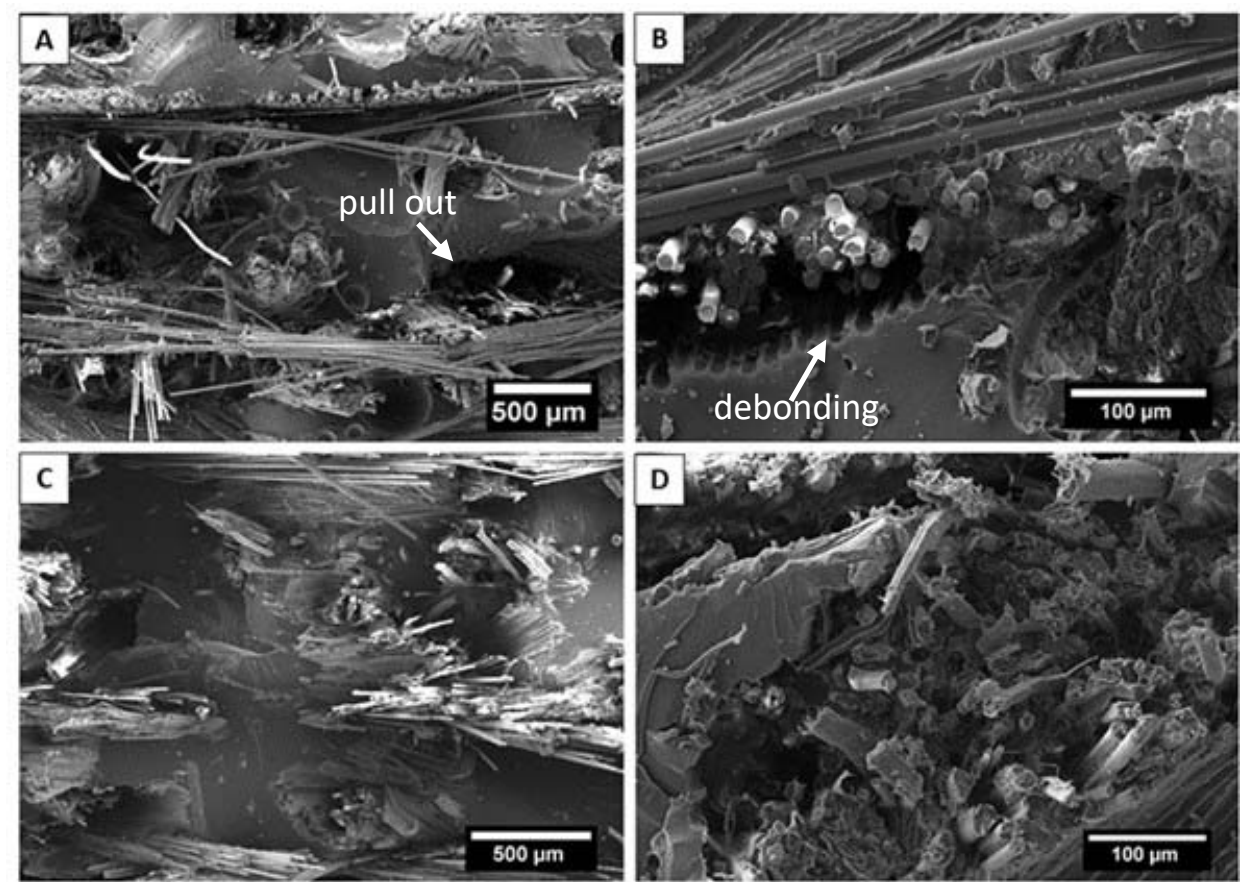

Fig. 15. FE-SEM micrographs of the basalt-flax hybrid composites after fatigue failure at stress level of $45 \% \sigma_{f}$. (A-B) $0^{\circ} / 90^{\circ}$ and $(\mathrm{C}-\mathrm{D}) \pm 45^{\circ}$ laminates. 


\section{Conclusions}

This paper deals with the analysis of the fatigue properties of basalt/epoxy, flax/epoxy and basaltflax/epoxy composite materials. Two different orientations are studied: $0^{\circ} / 90^{\circ}$ and $\pm 45^{\circ}$. An optimisation of the curing process was first carried out in order to reach the maximum level of crosslinking for the epoxy resin. Quasi-static tensile tests were conducted on the different composites obtained. The results showed that the hybrid composites were characterised by intermediate mechanical properties between those exhibited by flax and basalt composites. The combination of basalt with flax fibres allowed to obtain a composite material characterised by greater tensile strength than for $100 \%$ flax composites. Tensile-tensile fatigue tests were then performed. The results pointed out that the hybridisation was able to produce a positive effect on the normalised fatigue resistance of basalt laminates. The ability of flax fibres to absorb and deflect cracks allowed to obtain a hybrid composite with a better fatigue resistance compared to basalt laminates, without noticeable delamination at basalt/flax interface. These results highlight the effective interest in combining basalt and flax fibres to produce a composite material not only with limited cost and environmental impact but also with good mechanical performances. The positive results obtained in this work can encourage the possible application of flax-basalt hybrid composites in different industrial sectors, such as the automotive (for both interior and exterior parts), the aerospace (interior parts), the sport and leisure sectors.

\section{References:}

[1] Kiruthika AV. A review on physico-mechanical properties of bast fibre reinforced polymer composites. J. of Building Engineering. 2017; 9: 91-99. doi: 10.1016/j.jobe.2016.12.003.

[2] Gholampour A, Ozbakkaloglu T. A review of natural fiber composites: properties, modification and processing techniques, characterization, applications. J Mater Sci. 2020; 55: 829-892. https://doiorg.insis.bib.cnrs.fr/10.1007/s10853-019-03990-y.

[3] Koronis G, Silva A, Fontul M. Green composites: A review of adequate materials for automotive applications. Composites Part B: Engineering. 2013; 44(1): 120-127. doi:10.1016/j.compositesb.2012.07.004. 
[4] Chapman M, Dhakal HN. Effects of Hybridisation on the Low Velocity Falling Weight Impact and Flexural Properties of Flax-Carbon/Epoxy Hybrid Composites. FIBERS. 2019; 7(11): 95. DOI: 10.3390/fib7110095.

[5] Margabandu S, Subramaniam S. Experimental evaluation and numerical validation of bending and impact behaviours of hybrid composites with various stacking arrangements. Mater. Res. Express. 2019; 6: 125305, https://doi.org/10.1088/2053-1591/ab54e7.

[6] Supian ABM, Sapuan SM, Zuhri MYM, Zainudin ES, Ya HH. Hybrid reinforced thermoset polymer composite in energy absorption tube application: A review. Defence Technology. 2018; 14(4): 291-305. https://doi.org/10.1016/j.dt.2018.04.004.

[7] Abu Bakar MS, Salit MS, Mohamad Yusoff MZ, Zainudin, E.S., Ya, H.H. The crashworthiness performance of stacking sequence on filament wound hybrid composite energy absorption tube subjected to quasi-static compression load. Journal of Materials Research and Technology. 2020; 9(1): 654-666, https://doi.org/10.1016/j.jmrt.2019.11.006.

[8] Dong C. Review of Natural Fibre Reinforced Hybrid Composites. J. of Reinforced Plastics and Composites. 2018; 37(5): 331-348. https://doi.org/10.1177/0731684417745368.

[9] Sanjay MR, Madhu P, Jawaid M, Senthamaraikannan P, Senthil S, Pradeep S. Characterization and properties of natural fiber polymer composites: A comprehensive review. J. of Cleaner Production. 2018; 172: 566-581. doi: 10.1016/j.jclepro.2017.10.101.

[10] Rajesh M, Pitchaimani J. Mechanical and dynamic mechanical behaviour of novel glass-natural fibre intraply woven polyester composites. Sadhana-academy proceedings in engineering sciences. 2017; 42(7): 1215-1223. DOI 10.1007/s12046-017-0676-y.

[11] Mochane MJ, Mokhena TC, Mokhothu TH, Mtibe A, Sadiku ER, Ray SS et al. Recent progress on natural fiber hybrid composites for advanced applications : A review. Express Polymer Letters. 2019; 13(2): 159198. https://doi.org/10.3144/expresspolymlett.2019.15.

[12] Anand Chairman C, Jayasathyakawin S, Kumaresh Babu SP, Ravichandran M. Mechanical properties of basalt fabric plain and twill weave reinforced epoxy composites. Materials Today: Proceedings. 2020. https://doi.org/10.1016/j.matpr.2020.03.240.

[13] Chowdhury IR, Nash NH, Portela A, O'Dowd NP, Comer AJ. Analysis of failure modes for a non-crimp basalt fiber reinforced epoxy composite under flexural and interlaminar shear loading. Composite Structures. 2020; doi:https://doi.org/10.1016/j.compstruct.2020.112317. 
[14] Matykiewicz D, Barczewski M. On the impact of flax fibers as an internallayer on the properties of basaltepoxy composites modified with silanized basalt powder. Composites Communications. 2020; doi: https://doi.org/10.1016/j.coco.2020.100360.

[15] Dhakal H, Sarasini F, Santulli C, Tirillò J, Zhang Z, Arumugam V. Effect of basalt fibre hybridisation on post-impact mechanical behaviour of hemp fibre reinforced composites. Composites Part A: Applied Science and Manufacturing. 2015; 75: 54-67. https://doi.org/10.1016/j.compositesa.2015.04.020.

[16] Ricciardi MR, Papa I, Lopresto V, Langella A, Antonucci V. Effect of hybridization on the impact properties of flax/basalt epoxy composites: Influence of the stacking sequence. Composite Structures. 2019; 214: 476-485, https://doi.org/10.1016/j.compstruct.2019.01.087.

[17] Papa I, Ricciardi MR, Antonucci V, Pagliarulo V, Lopresto V. Impact behaviour of hybrid basalt/flax twill laminates. Composites Part B. 2018; 153: 17-25, https://doi.org/10.1016/j.compositesb.2018.07.025.

[18] Fiore V, Scalici T, Calabrese L, Valenza A, Proverbio E. Effect of external basalt layers on durability behaviour of flax reinforced composites. Composites Part B: Engineering. 2016; 84: 258-65. http://dx.doi.org/10.1016/j.compositesb.2015.08.087.

[19] Sarasini F, Tirillo J, Ferrante L, Sergi C, Russo P, Simeoli G et al. Quasi-Static and Low-Velocity Impact Behavior of Intraply Hybrid Flax/Basalt Composites. FIBERS. 2019; 7(3), 26. DOI: 10.3390/fib7030026.

[20] Matykiewicz D, Bogusławski M. Hybrid Epoxy Composites Reinforced with Flax Fiber and Basalt Fiber. In: Gapiński B., Szostak M., Ivanov V. (eds) Advances in Manufacturing II. 2019. Lecture Notes in Mechanical Engineering. Springer, Cham. DOI https://doi-org.insis.bib.cnrs.fr/10.1007/978-3-030-169435 55.

[21] Wang B, Lu H, Kim G. A damage model for the fatigue life of elastomeric materials. Mech Mater. 2002; 34(8): 475-483. https://doi.org/10.1016/S0167-6636(02)00175-8.

[22] Amiri M, Khonsari MM. Rapid determination of fatigue failure based on temperature evolution: fully reversed bending load. Int J Fatigue. 2010; 32(2): 382-389. https://doi.org/10.1016/j.ijfatigue.2009.07.015.

[23] Bensadoun F, Vallons KAM, Lessard LB, Verpoest I, Van Vuure AW. Fatigue behaviour assessment of flax-epoxy composites. Composites Part A: Applied Science and Manufacturing. 2016; 82: 253-266. https://doi.org/10.1016/j.compositesa.2015.11.003.

[24] Mahboob Z, Bougherara H. Fatigue of flax-epoxy and other plant fibre composites: Critical review and analysis. Composites Part A: Applied Science and Manufacturing. 2018; 109: 440-462. doi:10.1016/j.compositesa.2018.03.034. 
[25] Barbière R, Touchard F, Chocinski-Arnault L, Mellier D. Influence of moisture and drying on fatigue damage mechanisms in a woven hemp/epoxy composite: Acoustic emission and micro-CT analysis. International Journal of Fatigue. 2020; 136: 105593. https://doi.org/10.1016/j.ijfatigue.2020.105593.

[26] Liang S, Gning PB, Guillaumat L. A comparative study of fatigue behaviour of flax/epoxy and glass/epoxy composites. Composites Science and Technology. 2012;72: 535-43. https://doi.org/10.1016/j.compscitech.2012.01.011.

[27] Dorigato A, Pegoretti A. Fatigue resistance of basalt fibers-reinforced laminates. Journal of Composite Materials. 2012 ; 46(15): 1773-1785. DOI: 10.1177/0021998311425620.

[28] Zhao X, Wang X, Wu Z, Zhu Z. Fatigue behavior and failure mechanism of basalt FRP composites under long-term cyclic loads. International Journal of Fatigue. 2016; 88: 58-67. https://doi.org/10.1016/j.ijfatigue.2016.03.004.

[29] Wang X, Zhao X, Chen S, Wu Z. Static and fatigue behavior of basalt fiber-reinforced thermoplastic epoxy composites. Journal of Composite Materials. 2019; 0(0): 1-10. DOI:10.1177/0021998319896842.

[30] Sharba MJ, Leman Z, Sultan MTH, Ishak MR, Azmah Hanim MA. Partial replacement of glass fiber by woven kenaf in hybrid composites and its effect on monotonic and fatigue properties. BioResources. 2016; 11(1): 2665-83. DOI:10.15376/biores.11.1.2665-2683.

[31] Mostafa NH. Tensile and fatigue properties of Jute-Glass hybrid fibre reinforced epoxy composites. Mater. Res. Express 2019; 6: 125104. https://doi.org/10.1088/2053-1591/ab21f9.

[32] Sivakumar D, Ng LF, Lau SM, Lim KT. Fatigue Life Behaviour of Glass/Kenaf Woven-Ply Polymer Hybrid Biocomposites. J Polym Environ 2018; 26: 499-507. DOI: 10.1007/s10924-017-0970-0.

[33] Salman SD, Sharba MJ, Leman Z, Sultan MTH, Ishak MR, Cardona F. Tension-Compression Fatigue Behavior of Plain Woven Kenaf/Kevlar Hybrid Composites. BioResources. 2016; 11(2): 3575-3586. doi:10.15376/biores.11.2.3575-3586.

[34] Yuanyuan X, Guijun X. Hybrid basalt/flax fibers reinforced polymer composites and their use in confinement of concrete cylinders. Advances in Structural Engineering. 2020; 23(5): 941-953. https://doiorg.insis.bib.cnrs.fr/10.1177/1369433219886084.

[35] Abd El-baky MA, Attia MA, Abdelhaleem MM, Hassan MA. Mechanical characterization of hybrid composites based on flax, basalt and glass fibers. J. of Composite Materials. 2020; 0021998320928509. https://doi-org.insis.bib.cnrs.fr/10.1177/0021998320928509. 
[36] Fiore V, Scalici T, Calabrese L, Valenza A, Proverbio E. Effect of external basalt layers on durability behaviour of flax reinforced composites. Composites Part B: Engineering. 2016; 84: 258-265. https://doi.org/10.1016/j.compositesb.2015.08.087.

[37] Papa I, Ricciardi MR, Antonucci V, Pagliarulo V, Lopresto V. Impact behaviour of hybrid basalt/flax twill laminates. Composites Part B: Engineering. 2018; 153: 17-25. https://doi.org/10.1016/j.compositesb.2018.07.025.

[38] Živković I, Fragassa C, Pavlović A, Brugo T. Influence of moisture absorption on the impact properties of flax, basalt and hybrid flax/basalt fiber reinforced green composites. Composites Part B: Engineering. 2017; 111: 148-164. https://doi.org/10.1016/j.compositesb.2016.12.018.

[39] Seghini MC, Touchard F, Sarasini F, Chocinski-Arnault L, Mellier D, Tirillò J. Interfacial adhesion assessment in flax/epoxy and in flax/vinylester composites by single yarn fragmentation test: Correlation with micro-CT analysis. Composites Part A: Applied Science and Manufacturing, 2018; 113: 66-75. https://doi.org/10.1016/j.compositesa.2018.07.015.

[40] Seghini MC, Touchard F, Sarasini F, Cech V, Chocinski-Arnault L, Mellier et al. Engineering the interfacial adhesion in basalt/epoxy composites by plasma polymerization. Composites Part A: Applied Science and Manufacturing. 2019; 122: 67-76. https://doi.org/10.1016/j.compositesa.2019.04.013.

[41] Nunna S, Chandra PR, Shrivastava S, Jalan A. A review on mechanical behavior of natural fiber based hybrid composites. Journal of Reinforced Plastics and Composites. 2016; 31(11): 759-769. doi: $10.1177 / 0731684412444325$.

[42] Gupta K. Experimental investigation of the behavior of dual fiber hybrid composite under different stacking sequence. Proceedings of 17th Int. Conference on Composite Materials (ICCM-17), Edinburg, UK. 2009. http://iccmcentral.org/Proceedings/ICCM17proceedings/Themes/Industry/OFFSHORE\%20APPLICATIONS/INT\%2 0-\%20OFFSHORE\%20APPLICATIONS/IA6.2\%20Gupta.pdf

[43] Santulli C. Mechanical and Impact Damage Analysis on Carbon / Natural Fibers Hybrid Composites: A Review. Materials. 2019; 12(517): 1-17. doi: 10.3390/ma12030517.

[44] Shah DU, Schube, PJ, Clifford MJ, Licence P. Fatigue life evaluation of aligned plant fibre composites through S-N curves and constant-life diagrams. Composites Science and Technology. 2013; 74: 139-149. doi: 10.1016/j.compscitech.2012.10.015. 
[45] Degrieck J, Van Paepegem W. Fatigue Damage Modelling of Fibre-reinforced Composite Materials: Review. Applied Mechanics Reviews. 2001; 54(4): 279-300. https://doi.org/10.1115/1.1381395.

[46] Sevenois RDB, Van Paepegem W. Fatigue Damage Modeling Techniques for Textile Composites: Review and Comparison With Unidirectional Composite Modeling Techniques. Applied Mechanics Reviews. 2015; 67(2): 020802. https://doi.org/10.1115/1.4029691.

[47] D’Amore A, Caprino G, Stupak P, Zhou J, Nicolais L. Effect of stress ratio on the flexural fatigue behaviour of continuous strand mat reinforced plastics. Science and Engineering of Composite Materials. 1996; 5(1): 1-8. https://doi.org/10.1515/SECM.1996.5.1.1.

[48] Caprino G, D’Amore A. Flexural fatigue behaviour of randomcontinous-fibre-reinforced thermoplastic composites. Composites Science and Technology. 1998; 58(6): 957-965. doi: 10.1016/s02663538(97)00221-2.

[49] Caprino G, Giorleo G. Fatigue lifetime of glass fabric/epoxy composites. Composites Part A: Applied Science and Manufacturing. 1999; 30(3): 299-304. doi: 10.1016/S1359-835X(98)00124-9.

[50] Epaarachchi JA, Clausen PD. An empirical model for fatigue behavior prediction of glass fibre-reinforced plastic composites for various stress ratios and test frequencies. Composites Part A: Applied Science and Manufacturing. 2003; 34(4): 313-326. doi: 10.1016/S1359-835X(03)00052-6.

[51] Malpot A, Touchard F, Bergamo S. Fatigue behaviour of a thermoplastic composite reinforced with woven glass fibres for automotive application. Procedia Engineering. 2015; 133: 136-147.

DOI:10.1016/j.proeng.2015.12.641

[52] Toubal L, Karama M, Lorrain B. Damage evolution and infrared thermography in woven composite laminates under fatigue loading. International Journal of Fatigue. 2006; 28(12): 1867-1872. doi:10.1016/j.ijfatigue.2006.01.013.

[53] De Vasconcellos DS, Touchard F, Chocinski-Arnault L. Tension-tension fatigue behaviour of woven hemp fibre reinforced epoxy composite: A multi-instrumented damage analysis. International Journal of Fatigue. 2014; 59: 159-169. doi: 10.1016/j.ijfatigue.2013.08.029. 